\title{
EXISTIR E RE-EXISTIR: AS COMUNIDADES LGBTQIA+ NO BRASIL DE 2020
}

\author{
Existing and Re-existing: LGBTQIA+ Communities in 2020's Brazil
}

\author{
Daniel FERRAZ \\ Universidade de São Paulo \\ danielfe@usp.br \\ https://orcid.org/0000-0002-8483-2423 \\ Lucas MIQUELON \\ Iniciação Científica pela Universidade de São Paulo \\ lucas.miquelon@usp.br \\ https://orcid.org/0000-0003-0673-6070
}

Muito se fala, principalmente nas redes sociais, da expressão "Somos 70\%", em referência à oposição ao (des)governo atual do Brasil. Realmente queremos acreditar, ainda que sempre de modo reticente, que somos $85 \%$, mesmo com parte da imprensa nacional ainda tendo a coragem (e interesse!) em publicar notícias do tipo: "O atual presidente ganharia em 2022 em todos os cenários". Considerando que os governos anteriores de Lula da Silva e Dilma Rousseff (2003 a 2016) implementaram importantes políticas nacionais de proteção e empoderamento das mulheres e das comunidades LGBTQIA+ (BORBA, 2019), o atual governo (de 2019-2020) praticamente fez o contrário: sob o slogan "Brasil acima de tudo. Deus acima de todos", enfatiza continuamente sua indiferença e ódio em relação às comunidades LGBTQIA+, reafirmando repetidamente que o modelo de uma família brasileira deve ser o conservador e heteronormativo, e que todas as afetividades diferentes desse padrão não devem ser aceitas. Considerando que os ex-presidentes Lula e Dilma implementaram "o Ministério da Mulher, Igualdade Racial e Direitos Humanos, a lei que criminaliza a violência doméstica, a legalização do casamento entre pessoas do mesmo sexo, a implementação do projeto Brasil sem homofobia" (BORBA, 2019, p. 425 ), o movimento de extrema direita no Brasil garantiu que essas mudanças desagradassem a classe média conservadora. Num retorno à religiosidade, UMA religião, UM Deus (o deles!), o clã garantiu, em seu 
espalhamento de ataques às comunidades LGBTQIA+, mais desmerecimento e discriminação em relação as essas minorias, tod@/x/es, brasiler@/x/es, há de se registrar.

Infelizmente, o ocupante da mais alta posição política do país - e não o presidente, como Angela Davis colocou (DAVIS, 2019), não abandonou sua cruzada contra as pessoas LGBTQIA+. Em final de julho de 2020, uma discussão polarizada explodiu no Twitter e no Facebook: a campanha em que a Natura apresenta um pai trans para o dia dos pais. Bem, é risivelmente previsível que a família-clã tenha se posicionado veementemente contra; o pastor Silas Malafaia, de modo similar, convocou seus seguidores a cancelarem a Natura. Porém, as ações da empresa subiram e atingiram o primeiro lugar em valorização na Bolsa de São Paulo, algo que corrobora o pensamento dos $85 \%$ contra o desgovenro - embora entendamos que se trata de uma relação complexa, quando pensamos em consumo e representatividade. Thammy, o pai trans, não foi poupado, mesmo tendo sido a favor deste governo. É, car@ leitor/a, a Terra-Plana parece que gira: Agora Thammy vai se juntar à lista de desertores do poder? Aguardemos.

Recentemente, o ocupante parece ter pronunciado, em meio à pandemia, que “usar máscara é coisa de viado!”. Pronto, mais motivo para os machões fazerem o mesmo. Em 5 de março de 2019, ele twitou um vídeo pornográfico supostamente filmado durante o carnaval no Brasil. O vídeo/tweet foi banido do Twitter, mas a tentativa do ocupante de discriminar a comunidade e o carnaval brasileiro foi apoiada por muitos brasileiros que votaram nele. Quando uma pessoa que ocupa tal posição e supostamente representa politicamente uma nação, ataca as comunidades LGBTQIA+ durante o carnaval (feriado mais celebrado do Brasil, conhecido por sua felicidade e beleza), por meio de um vídeo, é possível perceber o tom generalizador e esteriotipante do qual ele faz uso, dando voz a ímpetos pessoais que ele julga poder publicizar.

Voltando um pouco no tempo, o ocupante lançou, em 20 de dezembro de 2019, um ataque homofóbico a um jornalista: "Você tem uma cara terrivelmente homossexual" fala que foi instantaneamente aplaudida por seus apoiadores. Em 2011, havia dito que seria “incapaz de amar um filho homossexual”. Já em 2002, declarou: "Não lutarei contra isso, nem discriminarei, mas se vejo dois homens se beijando na rua, vou espancá-los". É perceptível que, quando governantes - que supostamente seriam responsáveis por nutrir a diversidade - se tornam os primeiros a humilhar e desmoralizar as comunidades 
LGBTQIA+ com base em acontecimentos isolados transformados em verdades absolutas ou em explícita doutrinação religiosa, concedem ao cidadão permissão para fazer o mesmo (FERRAZ, 2019) .

Em 5 de junho de 2020, com a pandemia no ápice, hospitais à beira do colapso e sem substitutos no horizonte para o ministro da Saúde, o ocupante ameaçou retirar o país da Organização Mundial da Saúde (OMS), argumentando que, a menos que a agência “opere sem viés ideológico", ele seguiria a decisão dos EUA de encerrar o papel do país na organização. O discurso de que há um viés ideológico que marca sempre o outro, mas nunca esses atores da base governamentista é constante, especialmente quando observamos os pronunciamentos do agora ex-ministro da Educação - que, juntamente com o ocupante, coloca a esquerda, o comunismo e o socialismo no mesmo bojo - e, ao fazêlo, ignoram o fato de que eles estão impondo suas próprias ideologias.

Começamos a compreender, a partir disso, por que eles tentaram (e tentam, a partir dos mais diversos subterfúgios) impor uma "política não ideológica" no Brasil: se os livros não pretendem doutrinar, mas ensinar "Ciências e Matemática", as pessoas são levadas a acreditar que o ensino de outros assuntos - como sociologia, antropologia ou filosofia - é permeado pela "ideologia não desejada". Da mesma forma, quando o ocupante se humilha implorando a aceitação de Trump (a família-clã não somente postou, mas foi devota do dia de independência estadunidense), e Trump responde com o fechamento das portas dos EUA para o Brasil, ou mesmo quando Trump critica abertamente como o governo brasileiro vem lidando com a pandemia, é evidente que a decência nacional brasileira está em jogo. E, quando humilha especialmente as comunidades homossexuais e transgêneras, ele mostra sua incapacidade de respeitar outros seres humanos - brasileir@/x/es, há de se lembrar!

Como podemos perceber, as políticas recentes "buscam encontrar alternativas rápidas para problemas sociais complexos, recuperando uma das três estratégias atualmente usadas pelos Estados-nação em seu processo tradicional de se tornar um território unitário, quais sejam: assimilação, expulsão e extermínio" (DUBOC; FERRAZ, 2018, p. 233).Sim, car@ leitor/a, somos considerados um desastre nacional/internacional.

Prosseguimos com mais alguns argumentos. Quando o ocupante luta e distorce abertamente a homossexualidade em favor de sua cruzada para recuperar a "família 
tradicional e religiosa", ele provavelmente não reconhece seu próprio impulso homossexual declarado: referindo-se a reuniões de congressistas por meio de comentários como "estamos quase casados" e "foi um bom casamento", ele só é aceito porque representa a figura do homem heterossexual: vindo dele, esses comentários não passam de zombaria, porque esse é o lugar que a homossexualidade ocupa para ele e seu clã. Se tomarmos A História da Sexualidade (1978) como exemplo, perceberemos que o que Foucault faz é revelar e descortinar as relações de poder que são inerentes aos discursos da sexualidade. Como aponta, "o homossexual do século XIX se tornou uma personagem, um passado, uma história de caso e uma infância, além de ser um tipo de vida, uma forma de vida e uma morfologia, com uma anatomia indiscreta e possivelmente uma fisiologia misteriosa" (FOUCAULT, 1978, p. 43). Para o homossexual permaneceram (e ainda permancem) os rótulos dos diferentes, disfuncionais, misteriosos, abjetos, estranhos; "uma pessoa" que se tornou "um corpo" que, por sua vez, não passou de um "sexo" - um tipo que não era aceitável no conceito de família burguesa, construído pelas mãos da religião. Todas as outras formas possíveis de sexualidade, exceto a heterossexualidade, constituiram-se como inaceitáveis, uma vez que não estavam de acordo com a norma estabelecida; tem-se, diante disso, a formação discursiva da sexualidade, na qual a heteronormatividade é tida como única regra. As formações discursivas são, portanto, aquelas que governam as posições às quais o sujeito deve ser restringido, prescrevendo o conjunto de regras comum a todos os que a cumprem.

Às pessoas LGBTQIA+ é reservado um lugar, dentro da marginalidade, que se constitui como exercício material e simbólico de exclusão de corpos que, não se encaixando nessa norma, buscam resistir, de um modo ou de outro - aliás, o extenso acrônimo pode ser visto como uma tentativa de combater essa formação discursiva da sexualidade e desafiar a norma beligerante - tão querida para aquelas pessoas que, carregando seus eixos ilusórios da Verdade, tentam silenciar quem não conforma.

Nessa esteira de ideias, mais uma obviedade: a educação pública brasileira está sendo atacada. Em 31 de maio de 2019, o próprio ocupante menosprezou os milhões de professores e manifestantes, chamando-os de "idiotas inúteis" e "imbecis". Para piorar a situação, o agora ex-Ministro da Educação declarou recentemente: "Não quero nenhum sociólogo, antropólogo ou filósofo com o meu dinheiro". Essa afirmação captura a 
extensão do que discutimos: existe um regime muito específico da verdade sendo difundido por meio do discurso, pois o ministro produziu mais tensões e sobreposições que contribuem para reforçar um regime de verdade no qual os professores são de fato “idiotas inúteis" cuja principal preocupação é doutrinar os alunos.

Essa "mitigação do mundo acadêmico" ressoa às declarações públicas que o ocupante vem fazendo, especialmente aquelas com ataques desenfreados a Paulo Freire. No dia 29 de abril de 2019, ao ser entrevistado por uma menina de oito anos chamada Esther Castilho - uma youtuber convidada anteriormente para sua inauguração, ele defendeu que o Patrono da Educação Brasileira (título que Freire mantém desde 2012) "será mudado", apesar de não mencionar o filósofo. Certamente, essa atitude não deve causar nenhuma surpresa, pois, durante a campanha, ele declarou que "entraria no ministério da educação com um lança-chamas para remover Paulo Freire". Em 16 de dezembro de 2019, o seu comportamento combativo se destacou mais uma vez, ao chamar Freire de "ignorante" e "ídolo da esquerda". Em 20 de janeiro de 2020, o ocupante mostrou uma ânsia de mudar o sistema educacional brasileiro - que, segundo ele, é um “lixo baseado em Paulo Freire". Além do vocabulário lamentável, o ocupante insiste no desconhecimento das obras de Freire.

Para Walsh e Mignolo (2018), a pedagogia freireana é entendida aqui como uma metodologia essencial e indispensável, fundamentada nas realidades, subjetividades, histórias e lutas das pessoas. É nos contextos social, político, epistêmico e existencial da luta que "líderes e povos, mutuamente identificados, criam juntos as linhas diretivas de sua ação [educacional, política e de libertação]" (WALSH; MIGNOLO, 2018, p. 88). Um bom exemplo de como as forças conservadoras tentam agir através de meios institucionalizados para manter o status quo é o Programa Escola sem Partido, que se apresenta como uma forma de projeto imparcial, cujo objetivo seria impedir que os professores doutrinem os alunos, mas é, na verdade, uma tentativa explícita de desmantelar qualquer forma de diversidade, silenciando todo e qualquer ponto de vista que escapa à visão do ocupante e seu clã.

Infelizmente, essa é a nossa triste versão do Brasil de 2020. As sociedades contemporâneas, especialmente os países ocidentais, enfrentam o retorno do neoconservadorismo e uma validação extrema do neoliberalismo. Juntamente com esses 
movimentos, testemunhamos um desejo de homogeneidade, consenso, padronização, passividade, binarismos, polarizações e universalismo em várias relações sociais. Nesse sentido, o Brasil é um caso muito triste, para não dizer frustrante. Com a eleição de 2018 , os cidadãos brasileiros (pelo menos os 89 milhões que não votaram nele) e os educadores brasileiros enfrentaram um desafio hercúlico em relação à manutenção da democracia.

A relação entre o governo federal e o campo educacional, que deveria ser dialógica, acabou se tornando uma perseguição ideológica endossada e estimulada pela política desse governo, aliás, também em 2020, a Procuradoria Geral da República iniciou uma investigação para culpabilizar professores de universidades e outros que não se submetem ao autoritarismo. Parece-nos que o MUNDO está contra esse governo, inclusive os EUA, que acabaram de declarar: "Família B. Não se metam nas eleições americanas de 2020”. Assim, como dialogar com tudo isso? Qual é o nosso papel como educadores em contextos onde o silenciamento e a polarização, bem como a subsequente humilhação, incidem em nós? Por fim, como a educação linguística deve ser entrelaçada com as teorias de gênero, sexualidade e queer?

Temos que encerrar, por enquanto, essa conversa com você. Não oferecemos soluções, mas mais debate. Ao invés de oferecer respostas únicas, pensamos em dois movimentos autocríticos e convidamos o/a leitor/a a pensar em outros: O primeiro tem a ver com o fato de termos utilisado as mídias de massa e as redes sociais como materiais discursivos desta análise. Isso é conflitante e contraditório, uma vez que as mídias de massa e as redes sociais produzem seus próprios regimes manipuladores da verdade. Assim, temos que reafirmar nosso lócus de enunciação e estar cientes de nossas escolhas, cientes das armadilhas e falácias apresentadas pelas mídias em geral. Em relação à segunda autocrítica, reconhecemos que nascemos dentro de paradigmas modernos, tradicionais, conservadores, neoliberais-capitalistas e, mesmo que nos consideremos educadores críticos da linguagem, em termos freireanos, é muito difícil libertarmo-nos dessas correntes epistemológicas

Dito isto, acreditamos que as discussões aqui apresentadas são urgentes, especialmente nas áreas de educação linguística e formação de professores. Defendemos que a própria existência de pessoas LGBTQIA+ é um desafio: nossa re-existência é a prova de que a tal verdade única é uma falácia, uma ilusão que criaram; nossa re- 
existência é o questionamento diário da frágil solidez que arduamente tentam construir. Por fim, nossa re-existência e a de todas as comunidades e minorias que escapam à hegemonia é um apelo constante e em voz alta para questionar e suspender "a verdade". E assim continuamos, lutando para existir e resistir.

\section{REFERÊNCIAS}

BORBA, R. Gendered politics of enmity: language ideologies and social polarisation in Brazil. G\&L, v.13, n.4, p. 423-448, 2019.

DAVIS. A. Y. A liberdade é uma luta constante. Palestra. Parque do Ibirapuera, São Paulo, 2019. Disponível em: <https://www.youtube.com/watch?v=S-t1T0OxM9A> Acesso em: 31 ago. 2020.

DUBOC, A. P. M.; FERRAZ, D. M. Reading Ourselves: Placing Critical Literacies in Contemporary Language Education. Revista Brasileira de Linguística Aplicada, v.18, n.2, p.227-254, 2018.

FERRAZ, D. M. Visibilidade lgbtqia+ e educação linguística: por entre os discursos de ódio, aceitação e respeito. Revista X, v.14, p.200-221, 2019.

FREIRE, P. Pedagogy of the oppressed. London: Penguin Books, 1996.

FOUCAULT, M. The History of Sexuality, Vol. 1. New York: Pantheon Books, 1978.

WALSH, C.; MIGNOLO, W. On decoloniality: concepts, analytics, praxis. Durham and London: Duke University Press, 2018. 